\title{
Surgical treatment of type III acromioclavicular dislocation: Bosworth technique versus hook plating
}

\author{
Seyit Ali Gumustas, ${ }^{1}$ [D Fevzi Saglam, ${ }^{2}$ (i) Baran Komur, ${ }^{3}$ (i) Ahmet Guray Batmaz, ${ }^{4}$ \\ (D) Ismail Yukunc, ${ }^{5}$ (D) Haci Bayram Tosun, ${ }^{6}$ (D) Halil Ibrahim Bekler7 \\ ${ }^{1}$ Department of Orthopaedics and Traumatology, Dr. Lutfi Kirdar Kartal Training and Research Hospital, Istanbul, Turkey \\ 2Department of Orthopaedics and Traumatology, Sultanbeyli State Hospital, Istanbul, Turkey \\ ${ }^{3}$ Department of Orthopaedics and Traumatology, Kanuni Sultan Suleyman Training and Research Hospital, Istanbul, Turkey \\ ${ }^{4}$ Department of Orthopaedics and Traumatology, Istanbul Medipol University Faculty of Medicine, Istanbul, Turkey \\ ${ }^{5}$ Department of Orthopaedics and Traumatology, Yavuz Selim Bone disease and Rehabilitation Hospital, Trabzon, Turkey \\ ${ }^{6}$ Department of Orthopaedics and Traumatology, Adiyaman University Faculty of Medicine, Adiyaman, Turkey \\ ${ }^{7}$ Department of Orthopaedics and Traumatology, VM Medical Park Kocaeli Hospital, Kocaeli, Turkey
}

\begin{abstract}
OBJECTIVE: In this study, it was compared the clinical results of the Bosworth technique and hook plating in acromioclavicular (AC) dislocations.

METHODS: 44 patients are retrospectively evaluated in this study whom diagnosed as type III AC dislocations and treated by two different surgical methods in two different clinics. The patients were 30 males and 14 females with a mean age of 44 years (range, 18-80 years). The patients were divided into 2 groups according to the applied surgical technique. Group I comprised 25 patients to whom coracoclavicular fixation was applied by using the Bosworth technique. Group II comprised 19 patients to whom acromioclavicular fixation was applied by using hook plate. All patients are evaulated by The University of California at Los Angeles Shoulder Score (UCLA) and The disabilities of the arm, shoulder and hand (DASH) scoring system.

RESULTS: The mean follow-up period was 23 months (range, 12-42 months). A statistically significant diffference was determined between the surgical groups in respect of the modified UCLA scale $(p=0.012)$ and Quick DASH score ( $p=0.008)$. Hook plating group had better clinical results according to Bosworth group in terms of both UCLA and DASH score. A statistically highly significant negative correlation was determined between the UCLA and DASH scores $(r=0.677, p=0.000)$.
\end{abstract}

CONCLUSION: Although hook plating had better clinic outcomes compared to Bosworth technique, there is not seen difference between two groups in terms of the time of return to work. Treatment of the AC dislocation should perform early reconstruction for better reduction, fewer complications and higher levels of patient satisfaction.

Keywords: Acromioclavicular dislocation; bosworth technique; fixation; hook plating; results.

Cite this article as: Gumustas SA, Saglam F, Komur B, Batmaz AG, Yukunc I, Tosun HB, et al. Surgical treatment of type III acromioclavicular dislocation: Bosworth technique versus hook plating. North Clin Istanb 2018;5(4):334-340.

A s one of the most important joints around the shoulder, injuries to the acromioclavicular joint $(\mathrm{AC})$ are very important, as depending on the degree of injury, they cause restrictions to the daily life of the patient and workforce losses. Although several treatment methods have been described in literature, it has not been fully clarified which type of treatment is recommended for which type of dislocation [1-6]. The degree of injury and the functional expectations of the patient are the primary indicators. In type III AC joint injuries, there is a severe trauma

Received: November 05, 2017 Accepted: December 29, 2017 Online: December 29, 2017

Correspondence: Dr. Haci Bayram TOSUN. Adiyaman Universitesi Tip Fakultesi, Ortopedi ve Travmatoloji Klinigi, Adiyaman, Turkey. Tel: +90 5334497699 e-mail: bayramtosun@hotmail.com

(c) Copyright 2018 by Istanbul Northern Anatolian Association of Public Hospitals - Available online at www.kuzeyklinikleri.com 


\begin{tabular}{|c|c|c|c|c|}
\hline & Hook & Bosworth & $\mathrm{p}$ & Total \\
\hline Age & $46.05 \pm 7.28$ & $40.80 \pm 9.09$ & 0.053 & $43.06 \pm 8.67$ \\
\hline \multicolumn{5}{|l|}{ Gender } \\
\hline Female & $10(52.6)$ & $4(16)$ & $0.01 *$ & $14(31.8)$ \\
\hline Male & $9(47.4)$ & $21(84)$ & & $30(68.2)$ \\
\hline \multicolumn{5}{|l|}{ Side } \\
\hline Left & $4(21.1)$ & $11(44)$ & 0.11 & $15(34.1)$ \\
\hline Right & $15(78.9)$ & $14(56)$ & & $29(65.9)$ \\
\hline \multicolumn{5}{|l|}{ Dominant side } \\
\hline Left & $2(10.5)$ & $5(20)$ & 0.68 & $7(15.9)$ \\
\hline Right & $17(89.5)$ & $20(80)$ & & $37(84.1)$ \\
\hline \multicolumn{5}{|l|}{ Trauma type } \\
\hline Sport & $4(21.1)$ & $6(24)$ & & $10(22.7)$ \\
\hline Traffic accident & $5(26.3)$ & $4(16)$ & 0.70 & $9(20.5)$ \\
\hline Fall & $10(52.6)$ & $15(60)$ & & $25(56.8)$ \\
\hline Preoperative period (days) & $2.57 \pm 1.01$ & $4.32 \pm 1.49$ & $0.001 *$ & $3.56 \pm 1.56$ \\
\hline Hospitalization (days) & $4.68 \pm 1.15$ & $5.36 \pm 1.49$ & 0.11 & $5.06 \pm 1.38$ \\
\hline Follow-up (months) & $20.84 \pm 7.04$ & $25.12 \pm 9.72$ & 0.16 & $23.27 \pm 8.84$ \\
\hline
\end{tabular}

$* p<0.05$

with joint dislocation from tears of the $\mathrm{AC}$ ligament and capsule and tears of the coracoclavicular (CC) ligament. If evaluation is only made radiologically without making a thorough physical examination, there is a high possibility that these types of injuries will be overlooked [2,6-8].

In radiological comparison with the contralateral side, the CC ligament may be displaced by a distance of between $25 \%-100 \%[7,9]$. If adequate treatment is not applied to patients with type III AC injuries, it may be seen undesirable results such as pain, restricted movement of the shoulder joint, weakness around the shoulder, arthrosis in the AC joint, subluxation and re-dislocation, restriction of daily activities and sporting activities of the patient in the future. Therefore, it must be obtained stability of the AC joint without disrupting the movements and strenght of the shoulder in the ideal treatment [7].

In this study, we retrospectively evaluated the clinical results of Bosworth technique and hook plating in acromioclavicular $(\mathrm{AC})$ dislocations.

\section{MATERIALS AND METHODS}

In this study, a retrospective examination was made of a total of 44 patients who were surgically treated for type III acromioclavicular joint dislocation. All patients were given detailed information about this surgery, and approval was obtained. The patients were 30 males and 14 females with a mean age of 44 years (range, $18-80$ years). Group I comprised 25 patients to whom coracoclavicular fixation was applied using malleolar screw in the Bosworth technique $[6,10]$. Group II comprised 19 patients to whom acromioclavicular fixation was applied using hook plate with the $\mathrm{AO}$ technique [11]. The mechanism of injury was a fall in 25 cases, a sports injury in 10 and a traffic accident in 9 . The injury was on the right side in 29 patients and on the left in 15 and the mean time to surgery was 4 days (range, 1-8 days). Exclusion criterias were conservative treatment, concomitant clavicular fractures, chronic cases and those who had less than 1 year of follow-up (Table 1).

Postoperative functional evaluation was made using modified The University of California at Los Angeles Shoulder Score (UCLA) scale [12] and The disabilities of the arm, shoulder and hand (Quick DASH) scoring system [13]. In the modified UCLA scale 18-20 points was evaluated as very good, 15-17 points as good, 1214 points as fair and $<11$ points as poor.

The patients in group I were operated on under general anaesthesia in the semi-seated position by the same orthopaedic surgeon (SAG). The skin layers over the 

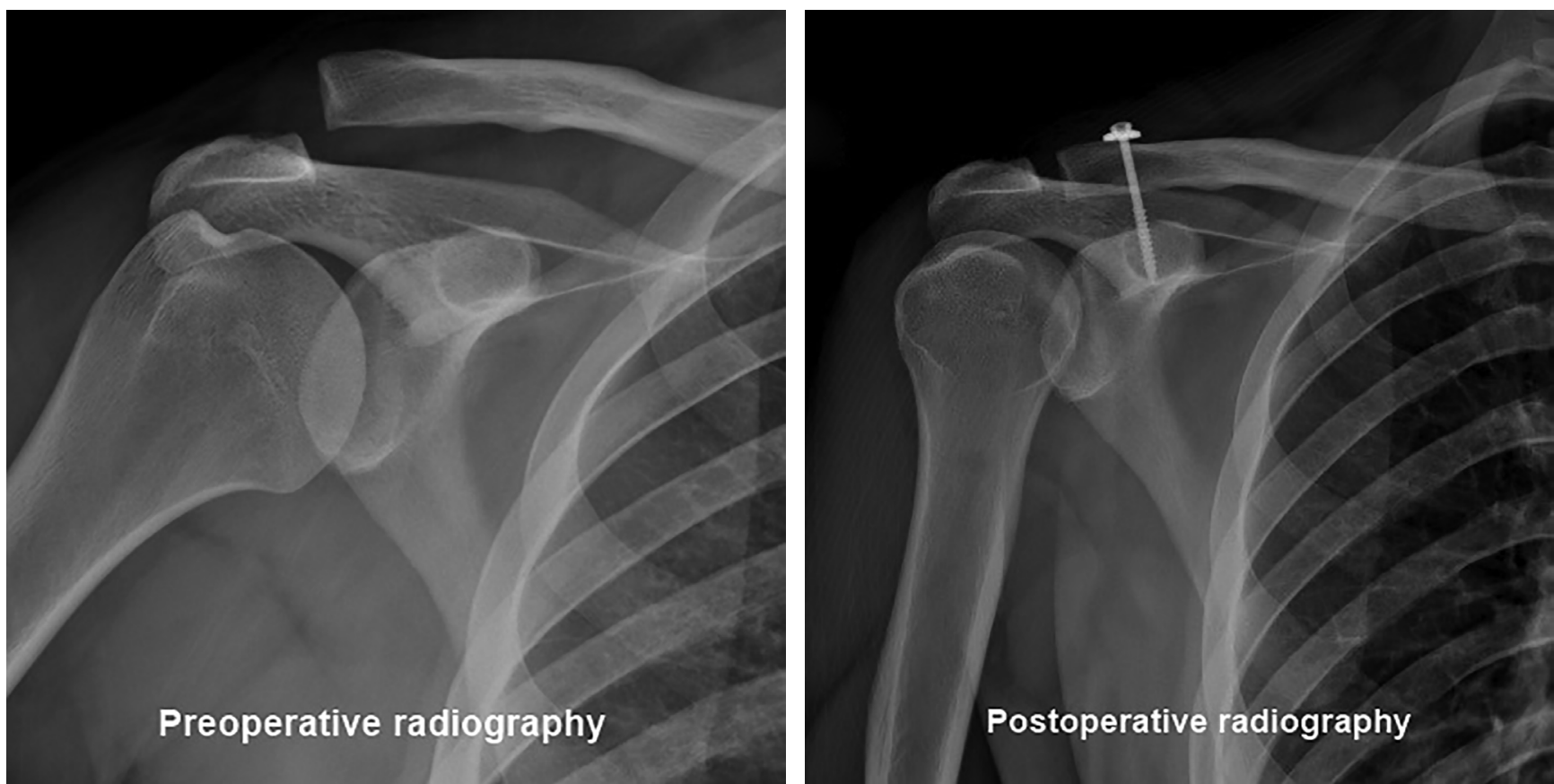

FIGURE 1. Bosworth technique radiography.

clavicle were entered with a parallel incision. After reduction of the AC joint, the clavicle and coracoid were drilled with a $3.2 \mathrm{~mm}$ drill. Only the superior cortex of the clavicle was hollowed with a $4.5 \mathrm{~mm}$ drill. Fixation was applied with one semi-cannulated spongeous screw (malleolar screw) of appropriate size and a washer (Fig. $1)$. In 3 patients, as there was a torn or subluxated disc which was preventing reduction of the $\mathrm{AC}$ joint, the disc was excised by extending the incision. It was not applied the CC ligament repair in any patient.
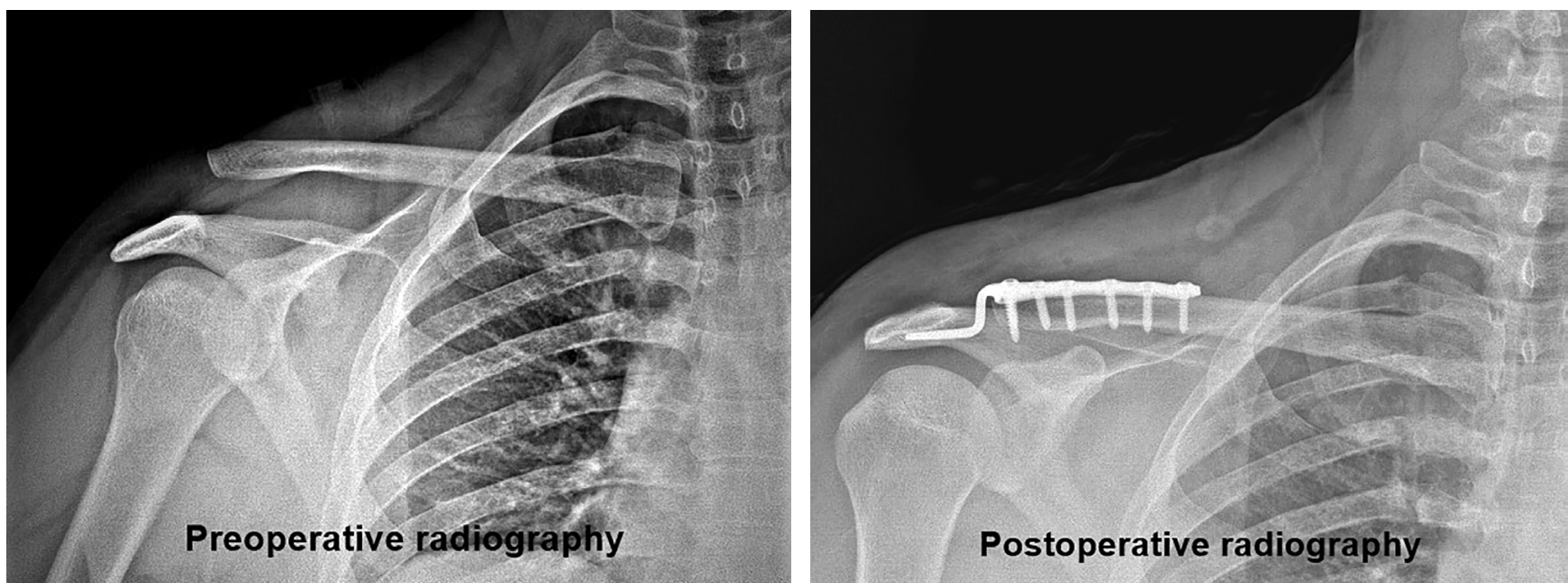

The patients in group II were operated on under general anaesthesia by another orthopaedic surgeon (IY). Entry was made with a straight incision of $5-6 \mathrm{~cm}$ starting from the distal of the clavicle and extending to the $\mathrm{AC}$ joint. After reduction of the joint by excision of the meniscus, fixation was applied with placement of a hook plate of appropriate size (Fig. 2).

Postoperative rehabilition protocols were not applied the same for each groups and patients. A shoulder-arm sling was used the all patients in the both groups for post-
Postoperative radiography

FIGURE2. Hook plate technique. 
operative 3 weeks, but it was allowed to remove the sling 4 or 5 times a day to do pendulum exercises. All patients were referred for physical therapy and passive and active joint range of movement exercises were started. It was not allowed to weight lift any objects over $1-2$ pounds and to elevate of operated arm above 90 degrees in any plane for a period of first 6 weeks. However, it was not allowed to elevate of operated arm above 90 degrees in any plane for patients in hook plate groups. The patients applied hook plate in contrast to Bosworth technique are not recommended the arm abduction over 90 degrees till implant removal. After 3 months, activities requiring strength were permitted. Complaints of excessive pain in the shoulder or restricted movement were considered to be due to the implant or insufficient material and after at least 6 months, all of the implants were removed.

Statistical analysis of the data was made using SPSS 17.5 statistics software program. In the comparison of categorical variables, the Chi-square test was used. Continuous variables with normal distribution were compared with the T-test and those not with normal distribution with the Mann Whitney U-test. A value of $\mathrm{p}<0.05$ was considered statistically significant.

\section{RESULTS}

The mean follow-up period was 23 months (range, 1242 months). The general distribution and according to the surgical groups is shown in Table 1. Postoperatively, the mean modified UCLA scale value was 16.6 (range, 14-19), the mean Quick DASH score was 14.5 (range, 2.2-26.8). According to the modified UCLA scale, 17 (38.6\%) patients were evaluated as very good, 22 (50.0\%) patients as good and $5(11.4 \%)$ patients as moderate (Table 2). No poor results were obtained in any patient. A statistically significant difference was determined between the surgical groups in respect of the modified UCLA scale $(p=0.012)$ and Quick DASH score $(p=0.008)$. Hook plating group had better clinical results according to Bosworth group in terms of both modified UCLA and DASH score. A statistically highly significant negative correlation was determined between the UCLA and DASH scores $(r=0.677, p=0.000)$ (Table 3).

Mean time for return to work of all the patients was 3.3 months (range, 2-6 months). No statistically significant difference was determined between the two groups in respect of the return to work $(\mathrm{p}=0.58)$. Removal of the fixation material was applied at mean 4.6 months (4.2 months for Bosworth technique, 5.1 months for Hook plating). At the final physical examination, all patients
TABLE 2. Comparison of modified UCLA scala in Group I and Group II

\begin{tabular}{lccc} 
& \multicolumn{3}{c}{ Group } \\
\cline { 2 - 4 } UCLA & Hook & Bosworth & Total \\
\hline $\begin{array}{l}\text { Very Good } \\
\quad \text { Count } \\
\% \text { within group }\end{array}$ & $52.6 \%$ & $28.0 \%$ & $38.6 \%$ \\
$\begin{array}{l}\text { Good } \\
\quad \text { Count }\end{array}$ & 6 & 10 & 22 \\
$\quad \%$ within group & $31.6 \%$ & $64.0 \%$ & $50.0 \%$ \\
$\begin{array}{l}\text { Moderate } \\
\quad \text { Count } \\
\quad \% \text { within group }\end{array}$ & $15.8 \%$ & $8.0 \%$ & $11.4 \%$ \\
$\begin{array}{l}\text { Total } \\
\quad \text { Count } \\
\quad \% \text { within group }\end{array}$ & $100.0 \%$ & $100.0 \%$ & $100.0 \%$ \\
\hline
\end{tabular}

UCLA: The University of California at Los Angeles Shoulder Score.

TABLE 3. Comparison between both groups of functional outcomes and time of return to work

\begin{tabular}{lccc} 
& $\begin{array}{c}\text { Hook } \\
\text { plating }\end{array}$ & $\begin{array}{c}\text { Bosworth } \\
\text { technique }\end{array}$ & $\mathrm{p}$ \\
\hline UCLA & $17.42 \pm 1.80$ & $16.12 \pm 1.26$ & $\mathbf{0 . 0 1 2 *}$ \\
DASH & $9.22 \pm 8.61$ & $18.58 \pm 4.30$ & $\mathbf{0 . 0 0 8 *}$ \\
Return to work (month) & $3.42 \pm 1.26$ & $3.24 \pm 0.72$ & 0.58 \\
\hline
\end{tabular}

UCLA: The University of California at Los Angeles Shoulder Score; DASH: The disabilities of the arm, shoulder and hand; ${ }^{*} \mathrm{p}<0.05$; A highly significant negative correlation was determined between the UCLA and DASH scores $(r=-0.677, p=0.000)$.

were observed to have full shoulder joint range of movement. During surgery, no complications such as vascular or nerve damage were encountered in any patient. A change in working or sporting activities had to be made in $3(6.8 \%)$ patients. We observe 1 hook plate breaking and 1 superficial wound infection that treated by antibiotherapy. We observe $5 \mathrm{AC}$ arthritis (4 was in hook plate group) and 3 reduction loss (2 in Bosworth group).

\section{DISCUSSION}

In this study, we compared the clinical outcomes of patients who underwent hook plating and Bosworth technique for type III AC dislocation. Hook plating group 
had better clinical results according to Bosworth group in terms of both modified UCLA $(\mathrm{p}=0.012)$ and DASH score $(p=0.008)$. No statistically significant difference was determined between both groups in respect of the return to work $(p=0.58)$. At the final physical examination after removal of implant, all patients were observed to have full shoulder joint range of movement.

Typically, acromioclavicular injuries result from direct trauma to the shoulder from a fall or in contact sports when the arm is in an adducted position. The force pushes the acromion inferiorly while the clavicle maintains its anatomic position, resulting in a variable disruption of the acromioclavicular and coracoclavicular ligaments [12]. Treatments are based on one of three types of fixation: acromioclavicular, coracoclavicular, and dynamic muscle transfer. These procedures can all be combined with ligament augmentation and/or resection of the distal clavicle [4]. Some authors have advocated conservative treatment in cases of acute Type III dislocations and recommend 2-8 weeks immobilization following reduction in these patients $[14,15]$.

There are some studies reported that results of conservative treatment were better than those of surgical treatment $[16,17]$. However, in young active patients with severe AC displacement of $>2 \mathrm{~cm}$, surgical treatment was recommended [6]. Galpin et al. [18] compared the conservative treatment method with surgical treatment using the Bosworth technique. They reported that the results of both techniques were reported to be similar even though there was a slight delay in return to work, sports and activity in the patients of the conservative treatment group [18]. Inadequate treatment results have been reported from conservative treatment characterized by pain, loss of strength and restricted movement in $20 \%$ of conservatively-treated patients with difficulties in tolerance and the development of cosmetic problems $[6$, $7,15,19,20]$. Therefore, many authors have advocated surgery in the treatment of acute AC dislocations [5-8]. Previous studies have shown the superiority of surgical treatment according to conservative treatment [14]. The basic aim of surgery is to obtain anatomic reduction and stable fixation. The disadvantages of surgery are the requirement for anaesthesia, the risk of infection and the possibility of degenerative arthritis [7, 20]. Superficial wound site infection following $\mathrm{AC}$ joint luxation has been reported in literature at rates of $0 \%-53 \%$ [1-3]. In our study, we carried out surgery for all Type III dislocations and observed one superficial infection whom healing by antibiotherapy.
When patients with $\mathrm{AC}$ dislocation are performed early reconstruction, it will be obtained better reduction, fewer complications and higher levels of patient satisfaction [21]. Weinstein et al. reported that worse results were obtained in cases where a period of more than 3 months had elapsed before surgery [22]. In our study, surgical treatment was applied to patients who presented within 10 days of the trauma and were evaluated as an acute injury. We carried out surgery for acute dislocations when patients applied to us and we exclude the patients whom undergone for late surgery.

Fukuda et al. emphasized that it is important the effects on stabilization and clinical outcomes of the ligament repair [23]. Ligament repair with the Bosworth technique is an effective technique in obtaining adequate shoulder functions with ease of application, a low complication rate and low rates of acromioclavicular joint arthritis $[2,3,24]$. The most common complication of surgical treatment is loss of reduction in the joint because of problems such as breakage or loosening of the screw $[3,6$, 25]. Bektaser et al. [2] reported that it is seen recurrence of dislocation in only $8.8 \%$ of patients treated with the modified Bosworth technique [2]. Although it has been reported that there may be mild pain and discomfort in the follow-up of cases with subluxation, the results of most of these cases have been good, and no relationship has been determined between the amount of subluxation and the outcome $[3,26]$. In our study, we didn't apply coracoclavicular ligament repair to any patient. We observed reduction loss in 2 patients who was performed Bosworth technique. For this reason, we think ligaments repair is important at stability and re-dislocation.

The rates of arthritis in the Bosworth technique are extremely low [3], but AC arthritis has been reported to be seen more often in cases where reduction could not be achieved [27]. Taft et al. [19] reported that in patients where anatomic reduction could not be achieved, although degenerative changes are generally seen radiographically, insufficient anatomic restoration did not effect the clinical results or patient satisfaction [19]. In our study, as there were complaints of excessive pain in one patients who developed arthritis following the Bosworth procedure, the material was removed. At 3 months postoperatively, the complaints of these patients were seen to have completely recovered. We observed AC arthritis in five patients but we did not perform acromioplasty to any patient.

A limitation of the modified Bosworth technique is 
the need for a second intervention to remove the screw [28]. A good balance must be struck between early removal of the screw to prevent breakage and the risk of deformity developing again. Otherwise, the recurrence of deformity may see at the high rate of $35 \%$ in literature $(3 / 3)$. It is usually recommended that the screw is removed in the $8^{\text {th }}$ week [6]. In our study, the screw was removed after the $3^{\text {rd }}$ month (3-7 months).

The hook-plate is a useful device for the treatment of unstable injuries in the acromioclavicular region. Although the main concern in the application of hook plate is subacromial impingement, good results have been obtained in many studies without this complication [29]. Koukakis et al. [30] suggested that extraction of the osteosynthetic material within 3 months because of the possibility of subacromial impingement. In our study, the plate was removed in one patient with pain due to the development of AC arthritis after hook plating, and the complaints were seen to recover.

Biomechanical complications can be observed in both techniques. Kienast et al. [31] reported that it was developed complications in $24(10.6 \%)$ of 225 patients, and the most common complication was reported to be redislocation after removal of the hook plate. Baets et al. [11] reported that despite $\mathrm{AC}$ joint changes and an increased CC distance compared to the healthy side, excellent and good clinical results after surgery were obtained. The clinical results of their study were reported to be better than the radiological results.

Kezunović et al. [5] have compared these two techniques in 28 patients with AC dislocation. They reported that postoperative complications were seen in 8 of the 16 patients in the Bosworth group and seen in only 2 of the 12 patients in hook plate group, but it was not statistically significant difference. However, the patient satisfaction and Constant scores of the hook plate group were determined to be statistically significantly high. Broos et al. [27] reported that it was no statistically significant difference between the Bosworth technique and hook plating in a long-term study of 87 patients with AC dislocation. In their study, high complication rates $(16 \% \mathrm{im}-$ plant failure, $25 \%$ redislocation, 39\% calcification, $41 \%$ arthritis) and low success rates (60\% very good and good results) were obtained. In our study, better functional results were obtained in the hook plate group without additional soft tissue interventions.

Previous studies have been generally recommended the application of a shoulder-arm sling for 1-4 weeks, but early functional motion is important and must avoid from limitations of shoulder motion $[1,3,24]$. In our study, a shoulder-arm sling was routinely applied for a period of 3 weeks postoperatively. During this period, shoulder pendulum exercises and wrist and elbow active exercises were permitted.

Limitations of this study are lack of long-term results and there is no control group of conservative. Also, the groups were not randomised and the design of the study was retrospective.

In conclusion, although hook plating had better clinic outcomes compared to Bosworth technique, there is no statistically significant difference between two groups in terms of the time of return to work. Treatment of the AC dislocation should perform early reconstruction for better reduction, fewer complications and higher levels of patient satisfaction. A good balance should be struck between the time of removal of the implants to prevent breakage of implant and recurrence of deformity.

Conflict of Interest: No conflict of interest was declared by the authors.

Financial Disclosure: The authors declared that this study has received no financial support.

Authorship Contributions: Concept - S.A.G., I.Y.; Design - S.A.G., I.Y.; Supervision - S.A.G., I.Y.; Materials - S.A.G., F.S., B.K., A.G.B., I.Y.; Data collection \&/or processing - S.A.G., F.S., B.K., A.G.B., I.Y.; Analysis and/or interpretation - S.A.G., B.K., I.Y., H.B.T.; Writing S.A.G., F.S., B.K., A.G.B., H.B.T.; Critical review - S.A.G., F.S., I.Y., H.B.T.

\section{REFERENCES}

1. Mardani-Kivi M, Mirbolook A, Salariyeh M, Hashemi-Motlagh K, Saheb-Ekhtiari K. The comparison of Ethibond sutures and semitendinosus autograft in the surgical treatment of acromioclavicular dislocation. Acta Orthop Traumatol Turc 2013;47:307-10. [CrossRef]

2. Bektaşer B, Bozkurt M, Oçgüder A, Solak S, Oğuz T. Surgical treatment of type III acromioclavicular joint dislocations by a modified Bosworth technique. Ulus Travma Acil Cerrahi Derg 2004;10:245-9.

3. Esenyel CZ, Oztürk K, Bülbül M, Ayanoğlu S, Ceylan HH. Coracoclavicular ligament repair and screw fixation in acromioclavicular dislocations. Acta Orthop Traumatol Turc 2010;44:194-8. [CrossRef]

4. Basyoni Y, El-Ganainy AE, Aboul-Saad M. Acromioclavicular joint reconstruction using anchor sutures: surgical technique and preliminary results. Acta Orthop Belg 2010;76:307-11.

5. Kezunović M, Bjelica D, Popović S. Comparative study of surgical treatment of acromioclavicular luxation. Vojnosanit Pregl 2013;70:292-7.

6. Bannister GC, Wallace WA, Stableforth PG, Hutson MA. The management of acute acromioclavicular dislocation. A randomised prospective controlled trial. J Bone Joint Surg Br 1989;71:848-50. [CrossRef]

7. Kaplan H, Kiral A, Kuskucu M, Arpacioglu MO, Sarioglu A, Rodop O. Report of eight cases of humeral fracture following the throwing of 
hand grenades. Arch Orthop Trauma Surg 1998;117:50-2. [CrossRef]

8. Li X, Ma R, Bedi A, Dines DM, Altchek DW, Dines JS. Management of acromioclavicular joint injuries. J Bone Joint Surg Am 2014;96:7384. [CrossRef]

9. Rockwood CA Jr. Injuries to the acromioclavicular joint. In: Rockwood CA Jr, Green DP. Fractures in adults. Vol 1. 2nd ed. Philadelphia: JB Lippincott; 1984. p 860-910.

10. Bosworth BM. Acromioclavicular separation: New method of repair. Surg Gynecol Obstet 1941;73:866-71.

11. De Baets T, Truijen J, Driesen R, Pittevils T. The treatment of acromioclavicular joint dislocation Tossy grade III with a clavicle hook plate. Acta Orthop Belg 2004;70:515-9.

12. Algarín JR, Salcedo JD, Rodríguez JO, Bello AG, Sancho FB. Grade III acromioclavicular dislocation treated with a minimally invasive approach. [Article in Spanish]. Acta Ortop Mex 2010;24:317-23.

13. Gummesson C, Ward MM, Atroshi I. The shortened disabilities of the arm, shoulder and hand questionnaire (QuickDASH): validity and reliability based on responses within the full-length DASH. BMC Musculoskelet Disord 2006;7:44. [CrossRef]

14. Darrow JC Jr, Smith JA, Lockwood RC. A new conservative method for treatment of Type III acromioclavicular separations. Orthop Clin North Am 1980;11:727-33.

15. Schlegel TF, Burks RT, Marcus RL, Dunn HK. A prospective evaluation of untreated acute grade III acromioclavicular separations. Am J Sports Med 2001;29:699-703. [CrossRef]

16. Glick JM, Milburn LJ, Haggerty JF, Nishimoto D. Dislocated acromioclavicular joint: follow-up study of 35 unreduced acromioclavicular dislocations. Am J Sports Med 1977;5:264-70. [CrossRef]

17. Dias JJ, Steingold RF, Richardson RA, Tesfayohannes B, Gregg PJ. The conservative treatment of acromioclavicular dislocation. Review after five years. J Bone Joint Surg Br 1987;69:719-22. [CrossRef]

18. Galpin RD, Hawkins RJ, Grainger RW. A comparative analysis of operative versus nonoperative treatment of grade III acromioclavicular separations. Clin Orthop Relat Res 1985:150-5. [CrossRef]

19. Taft TN, Wilson FC, Oglesby JW. Dislocation of the acromioclavicular joint. An end-result study. J Bone Joint Surg Am 1987;69:1045-51.

20. Lancaster S, Horowitz M, Alonso J. Complete acromioclavicular separations. A comparison of operative methods. Clin Orthop Relat Res
1987:80-8.

21. Rolf O, Hann von Weyhern A, Ewers A, Boehm TD, Gohlke F. Acromioclavicular dislocation Rockwood III-V: results of early versus delayed surgical treatment. Arch Orthop Trauma Surg 2008;128:1153-7.

22. Weinstein DM, McCann PD, McIlveen SJ, Flatow EL, Bigliani LU. Surgical treatment of complete acromioclavicular dislocations. Am J Sports Med 1995;23:324-31. [CrossRef]

23. Fukuda K, Craig EV, An KN, Cofield RH, Chao EY. Biomechanical study of the ligamentous system of the acromioclavicular joint. J Bone Joint Surg Am 1986;68:434-40. [CrossRef]

24. Weitzman G. Treatment of acute acromioclavicular joint dislocation by a modified Bosworth method. Report on twenty-four cases. J Bone Joint Surg Am 1967;49:1167-78. [CrossRef]

25. Pavlik A, Csépai D, Hidas P. Surgical treatment of chronic acromioclavicular joint dislocation by modified Weaver-Dunn procedure. Knee Surg Sports Traumatol Arthrosc 2001;9:307-12. [CrossRef]

26. Graupe F, Dauer U, Eyssel M. Late results of surgical treatment of Tossy III acromioclavicular joint separation with the Balser plate. [Article in German]. Unfallchirurg 1995;98:422-6.

27. Broos P, Stoffelen D, Van de Sijpe K, Fourneau I. Surgical management of complete Tossy III acromioclavicular joint dislocation with the Bosworth screw or the Wolter plate. A critical evaluation. [Article in German]. Unfallchirurgie 1997;23:153-9. [CrossRef]

28. Law KY, Yung SH, Ho PY, Chang HT, Chan KM. Coracoclavicular ligament reconstruction using a gracilis tendon graft for acute type-III acromioclavicular dislocation. J Orthop Surg (Hong Kong) 2007;15:315-8. [CrossRef]

29. Faraj AA, Ketzer B. The use of a hook-plate in the management of acromioclavicular injuries. Report of ten cases. Acta Orthop Belg 2001;67:448-51.

30. Koukakis A, Manouras A, Apostolou CD, Lagoudianakis E, Papadima A, Triantafillou $\mathrm{C}$, et al. Results using the $\mathrm{AO}$ hook plate for dislocations of the acromioclavicular joint. Expert Rev Med Devices 2008;5:567-72. [CrossRef]

31. Kienast B, Thietje R, Queitsch C, Gille J, Schulz AP, Meiners J. Mid-term results after operative treatment of rockwood grade III-V acromioclavicular joint dislocations with an AC-hook-plate. Eur J Med Res 2011;16:52-6. [CrossRef] 